\title{
DoIS EM UM (NOTAS SOBRE TESE E ANTÍTESE $E$ $O$ DISCURSO E A CIDADE)
}

\author{
JOAQUIM ALves de AgUIAR
}

Universidade de São Paulo

\section{Resumo}

$\mathrm{O}$ artigo propõe uma leitura conjunta de dois livros fundamentais de Antonio Candido: Tese e antítese (1964) e O discurso e a cidade (1993). A ideia é a de que um livro continua o outro, sendo ambos "amarrados" segundo o tema da humana luta pela felicidade.
Abstract

The paper offers a joint reading of two fundamental books by Antonio Candido: Tese e antitese (1964) and $O$ discurso e a cidade (1993). The idea is that the latter is a continuation of the first, the link between them being the theme of the human struggle for happiness.
Palavras-chave

Antonio

Candido;

Crítica

brasileira;

Método de

análise literária

Keywords
Antonio
Candido;
Brazilian
criticism;
Literary analysis method. 
m 1989, ${ }^{1}$ lendo pela primeira vez de ponta a ponta a Formação da literatura brasileira, tive a ideia de propor aos professores de literatura da Unicamp, onde eu era aluno de Pós-Graduação, que valeria a pena chamar Antonio Candido para falar do seu livro, na época, completando trinta anos de publicação. Organizado o evento - uma mesa simples, só com ele, ventilou-se, na ocasião, que a Formação não estaria entre os livros preferidos de sua autoria. Qual seria então a obra de sua preferência? Tese e antítese - ouvi dizer. Naquela altura, faltavam quatro anos para aparecer $O$ discurso e a cidade. Quase trinta anos separariam o primeiro livro do segundo, pois Tese e antítese é de 1964 e O discurso e a cidade de 1993. O que sugiro aqui é uma leitura conjunta dos dois, como se fossem um só livro - o segundo continuando o primeiro -, atento, basicamente, à estrutura de ambos, ou seja, ao modo como possivelmente foram concebidos e armados, sem me deter nas particularidades dos ensaios, o que levaria a trabalho de maior fôlego e tamanho. Por razões de familiaridade um pouco maior com o livro mais recente, vou começar por ele, chamando adiante o anterior, na tentativa de validar a sugestão.

O discurso e a cidade contém doze ensaios organizados em três partes ou seções. Na primeira, que dá título ao volume, Antonio Candido analisa quatro romances, a saber: Memórias de um sargento de milícias, L'Assommoir, I Malavoglia e O cortiço. Em suas análises, o crítico põe em prática o que denominou "método de redução estrutural", quer dizer, "o processo por cujo intermédio a realidade do mundo e do ser se torna, na narrativa ficcional, componente de uma estrutura literária, permitindo que esta seja estudada em si mesma, como algo autônomo"2.

\footnotetext{
${ }^{1}$ Essas notas se originaram no curso Seminários de Teoria Literária: Ensaios de Antonio Candido, que ministrei no primeiro semestre de 2003, junto ao Programa de Pós-Graduação em Teoria Literária e Literatura Comparada da FFLCH-USP. Foi onde conheci Leopoldo Waizbort, que também vinha tratando das ligações entre esses dois livros de Antonio Candido; no caso, pelo prisma de Erich Auerbach. Para acompanhar o seu trabalho e as conclusões a que chegou, ver, de sua autoria: Waizbort, Leopoldo. A passagem do três ao um. São Paulo, Cosac Naify, 2007.

${ }^{2}$ Antonio Candido. O discurso e a cidade. São Paulo, Duas Cidades, 1993, p. 9.
} 
Com efeito, no romance de Manuel Antonio de Almeida, o ritmo desprendido da vida de um segmento social brasileiro é captado pelo escritor que, entre outras coisas, produziu um enredo oscilante entre a crônica e o romance propriamente dito. Já em L'Assommoir, de Émile Zola, Antonio Candido mostra como as descrições do ambiente pelo qual transitam os personagens reforçam a narrativa do conflito - a vida dos pobres num cortiço parisiense. No terceiro estudo, o crítico se detém no romance de Giovanni Verga para mostrar o feito do autor: o romancista "inventou" uma linguagem para mostrar e falar de um mundo que não era o seu - o de um vilarejo de pescadores sicilianos, logrando uma solução estilística na qual a voz narrativa "não se distingue qualitativamente da dos personagens, escolhidos noutra esfera social". ${ }^{3}$ Finalmente, no romance de Aluísio Azevedo o preconceito contra o trabalho, na forma do preconceito contra o elemento estrangeiro, que suga as energias do brasileiro pobre, é internalizado na fatura do livro, que acaba aderindo à xenofobia e ao esquematismo naturalista.

Os leitores de $O$ discurso e a cidade estão vendo: minha sumária descrição nem de longe consegue indicar a força dos conteúdos dessa primeira parte do livro. Para começar, encontram-se ali dois dos ensaios mais fulgurantes de Antonio Candido. Refiro-me, é claro, a "Dialética da malandragem" (sobre Manuel Antonio) e a "De cortiço a cortiço" (sobre Aluísio), textos cuja força analítica e dialética merecerem, como se sabe, dois estudos alentados de Roberto Schwarz. ${ }^{4}$ Além disso, a leitura de "Degradação do espaço" (sobre Zola) e "De cortiço a cortiço" constitui, até onde sei, a mais bem-sucedida aplicação do método de literatura comparada no âmbito da crítica brasileira. E mais: os quatro ensaios da seção, quando lidos em conjunto, formam uma espécie de tratado sobre as relações do Naturalismo com suas representações do espaço, constituindo fonte preciosa para quem se debruça nos problemas da figuração deste elemento estrutural das narrativas em obras modernas. ${ }^{5} \mathrm{O}$ interessante, ainda, é que sobre esta gama toda de questões reina a lição de método de análise, que permite o exame, na fatura dos romances, da realidade que os mesmos souberam transfigurar. Em suma, sobram ali problemas críticos, e o conjunto, que realmente merece estudo à parte, constitui matéria da maior relevância no campo dos estudos literários.

São esses, portanto, os quatro ensaios que compõem a primeira parte de $O$ discurso e a cidade. Para além dos temas em comum e, sobretudo, do método analítico, que leva Antonio Candido a mostrar "de que maneira a narrativa se constitui a partir de materiais não literários, manipulados a fim de se tornarem aspectos

${ }^{3} \mathrm{O}$ discurso e a cidade, p. 105.

${ }^{4}$ Cf. Roberto Schwarz. "Pressupostos, salvo engano, de 'Dialética da malandragem"'. In: Que horas são? São Paulo, Companhia das Letras, 1987, pp. 129-155; e "Adequação nacional e originalidade crítica”. In: Sequêencias brasileiras. São Paulo, Companhia das Letras, 1999, pp. 24-45.

${ }^{5} \mathrm{Na}$ época de publicação (em revista) do primeiro ensaio do livro, "Dialética da malandragem", de 1970, Antonio Candido ministrava, na USP, curso de graduação denominado "A representação do meio ambiente no romance naturalista". Cf. o seu Memorial para concurso de professor titular, de 1974 (mimeografado). 
de uma organização estética regida pelas suas próprias leis", ${ }^{6}$ eles se juntam pela epígrafe, uma citação do romance A cidade invisível, de Ítalo Calvino: "Ninguém sabe melhor do que tu, sábio Kublai, que nunca se deve confundir a cidade com o discurso que a descreve. No entanto, há uma relação entre ambos". Como se vê, o título do livro foi tirado daí, com uma alteração importante: no texto de Calvino a cidade aparece antes do discurso e na citação de Antonio Candido depois. O detalhe tem a ver com o método, pois no trabalho do crítico a cidade está contida no discurso - a "redução estrutural", ou seja, é partindo da forma que ele estabelece a "relação entre ambos", isto é, a realidade própria da obra e o mundo que a engendrou.

Há outros elementos de ligação entre os ensaios, tais como o fato de os romances serem todos do século XIX - sendo os três últimos filiados à estética naturalista; e o fato de serem narrativas de cunho popular, no sentido de concentrarem seus enredos na representação dos pobres - sua vida, sua linguagem, sua cultura, suas aventuras e desventuras num mundo regido pela luta de classes. Sobre o assunto, talvez seja interessante lembrar que tais estudos foram publicados originalmente em revistas entre os anos de 1970 e 1974. Como se sabe, o país passava então pelo pior período da ditadura: a resistência ao obscurantismo, à injustiça e à violência era questão de ordem nos setores mais esclarecidos da sociedade brasileira. Por este prisma, podemos apreender a força política desses escritos originalmente dispersos em periódicos de circulação restrita. Neles, Antonio Candido não deflagra guerra aberta ao arbítrio. A rebeldia dos textos ou, se quisermos, o seu radicalismo, nasce da escolha do objeto voltado para os despossuídos, mas também se realiza no método de análise, que permite ao crítico observar de que maneira as injustiças sociais são internalizadas nos romances em estudo. Sendo assim, o espectro da ditadura que exclui e massacra, parece rondar os quatro estudos. E convém lembrar: a ditadura é uma espécie de morte - ela dissolve os contornos do indivíduo, rompe com os princípios da cidadania, expulsa ou elimina adversários, amordaça os descontentes etc.

Nos termos do prefácio do livro, esta primeira parte se opõe à segunda, onde, no lugar da análise de romances de corte realista, encontraremos estudos de textos que, por assim dizer, escapam ao realismo, sobretudo se o termo for encarado em sentido tradicional. Poderíamos pensar no primeiro bloco como abordagem da "vida real" e no seguinte como abordagem da questão do tempo? Provavelmente sim, até porque esta parte do livro se chama "Quatro esperas". Na verdade, as quatro esperas formam um ensaio único, organizado em quatro tópicos, sendo o primeiro voltado para um poema de Cavafis ("À espera dos bárbaros"), o segundo para um conto-novela de Kafka ("A muralha da China"), o terceiro para um romance de Dino Buzzati (O deserto dos tártaros), e o último para um romance de Julien Gracq (O litoral das sirtes). Diferentemente dos estudos da primeira parte, temos aqui textos do século XX, cujo assunto são "perigos iminentes, quase

${ }^{6} \mathrm{O}$ discurso e a cidade, p. 9. 
sempre com suspeita de catástrofe" . ${ }^{7}$ Não há nessas estórias "localização histórica nem geográfica precisa"; 8 elas criam "mundos arbitrários" e descrevem "sociedades imaginadas". ${ }^{9}$ São, portanto, representações antirrealistas, se comparadas às da seção anterior.

Observando os quatro tópicos, ou movimentos do ensaio, vemos um crescente de transfiguração: do poema descritivo de Cavafis à narrativa altamente metafórica de Julien Gracq. Há também uma ampliação no plano dos gêneros: do poema ao romance, e no meio deles o conto de Franz Kafka. O tema da ameaça de destruição alinhava as análises - nelas, encontramos civilizações, ou pedaços de civilização, em ruínas e na iminência da guerra. São narrativas de fundo histórico nas quais a morte, agora de maneira mais explícita, paira como um fantasma.

As quatro esperas são vistas a partir de quatro espaços: a cidade, a muralha, a fortaleza e a marinha. São lugares inventados, algo fabulosos e estranhos, como convém a um capítulo baseado na realidade transportada a regiões-limite. A epígrafe do ensaio é das mais expressivas. Trata-se de uma citação de Giuseppe Verdi: "Copiar a realidade pode ser uma coisa boa; mas inventar a realidade é melhor, muito melhor". Como se vê, o músico italiano elogia a invenção, o que deixaria para trás as narrativas da parte anterior, onde também se inventa, embora sejam invenções mais coladas à realidade, com tempo e espaço bem determinados. Sendo assim, torna-se interessante tomar em conjunto essas duas partes do livro. De certa maneira, elas formam uma tese e uma antítese - sociedade concreta e realismo de um lado; sociedade imaginada e fuga do realismo de outro. Se tal relação for possível, não se torna difícil ver, através dela, a ligação que pressentimos entre $\mathrm{O}$ discurso e a cidade e Tese e antítese.

Os livros, repetindo, separados por quase três décadas, contêm exclusivamente ensaios de análise de obras e autores, distinguindo-se de outros trabalhos de Antonio Candido, onde pode haver perfis, esquemas, discussões teóricas e amplos panoramas. São dois volumes de crítica, estritamente falando. Os problemas sociais e humanos são vistos a partir da análise detida das obras escolhidas pelo crítico. Em Tese e antítese, o conjunto de ensaios (sobre Alexandre Dumas, Eça de Queirós, Joseph Conrad, Graciliano Ramos, Guimarães Rosa, e mais Stendhal, cujo estudo Antonio Candido chama "espécie de apêndice do livro") é amarrado segundo "problemas de divisão ou alteração, seja na personalidade do escritor, seja no universo da sua obra". ${ }^{10}$ Tudo começa com a aventura romântica do Conde de Monte Cristo, ensaio decisivo e dos mais belos que o crítico escreveu. No romance de Alexandre Dumas, Antonio Candido investiga "a correlação que pode haver entre um certo momento da história e a formação de um tipo

${ }^{7} \mathrm{O}$ discurso e a cidade, p. 12.

${ }^{8}$ Idem, p. 12.

${ }^{9}$ Idem, p. 12

${ }^{10}$ Antonio Candido. Tese e antítese. 3a. ed, São Paulo, Nacional, 1978 (ver Prefácio, em páginas não numeradas). 
correspondente de herói literário". ${ }^{11}$ No caso, vemos a imagem de um homem transformado noutro homem, devido às circunstâncias. Um novo ser se desdobra do ser, dando a medida da "complexidade contraditória de cada um". ${ }^{2}$ De acordo com Candido, o Romantismo teria posto o problema "em primeira plana". E como vivemos um longo pós-Romantismo, assunto ao qual o crítico retornaria, ${ }^{13}$ o conflito permanece vivo: ainda sentimos "que os anjos e as bestas trafegam livremente em todos nós". ${ }^{14}$

Se no livro de 1964 a tese e a antítese se manifestam no ser, e em função da dinâmica da vida, no livro de 1993 elas se manifestarão no método de organização do volume e em função do repertório escolhido. A depuração daí decorrente dispensa comentários. E indica longa elaboração. Poderíamos pensar que Antonio Candido evoluiu de uma crítica mais temática para uma crítica mais analítica? Sim e não porque a resposta depende muito do modo de ler os seus ensaios. Creio haver consenso relativo à sua busca de "redução estrutural", mas é preciso notar que tal busca não se deu da noite para o dia, nem certamente teve data marcada. A época dos estudos de Tese e antítese - a maioria dos anos de 1950 - nos chama a atenção: é como se o crítico estivesse gestando obra no "anexo" da principal, cujas implicações sociológicas são amplamente reconhecidas. Se as coisas forem do jeito que estamos imaginando, encontramos uma espécie de segunda divisão nos escritos de Antonio Candido. A primeira dizia respeito à Sociologia e à Literatura; a segunda, como estamos vendo, ao seu interesse tanto pela Literatura Social quanto pela Literatura de implicações mais existenciais. De algum modo, no tema da divisão do ser, examinado em Tese e antítese, e retomado, de forma ainda mais sutil, em $O$ discurso e a cidade, projeta-se uma face do crítico, até onde sei, pouco abordada. O conflito entre o homem e a sociedade é, por assim dizer, transposto para o interior do mesmo homem, que se divide e pode surpreender a si mesmo e ao outro.

Separar os dois seria mais fácil - para trás o crítico sociológico, para frente o "existencialista" -, o que, entretanto, não faria jus ao trabalho de Antonio Candido, que sempre juntou as duas vertentes. ${ }^{15}$ Digamos assim: as misérias da vida social põem por terra a ilusão da integridade do ser, e o conflito daí resultante, e à distância da metafísica, acaba espelhando o método analítico, que investiga nas obras a internalização do que a elas seria externo. No meu entender reside aí o nervo dialético desses ensaios admiráveis.

Com efeito, tal preocupação acompanha a obra do crítico, desde o início. O estudo sobre O Conde de Monte Cristo data de 1952, quando foi publicado pela

${ }^{11}$ Idem, ibidem.

${ }^{12}$ Idem, ibidem.

${ }^{13}$ Ver de Antonio Candido. "O Romantismo, nosso contemporâneo". In: Jornal do Brasil, 19/3/1988, Suplemento "Idéias", pp. 6-7.

${ }^{14}$ Prefácio à Tese e antítese.

${ }^{15}$ Só para lembrar: o tema da espera, que rege a parte intermediária do livro de 1993, já havia regido a análise do poema "Leito de folhas verdes", de Gonçalves Dias, na Formação da literatura brasileira, livro cuja redação, segundo Antonio Candido, foi concluída em 1957. 
primeira vez, em versão menor. Cinco anos depois, em 1957, apareceria "Catástrofe e sobrevivência", sobre Joseph Conrad, no Suplemento Literário do Estadão, depois recolhido, como o anterior, em Tese e antítese. Este ensaio ocupará o centro do livro, onde será o mais extenso, espécie de eixo do conjunto de seis estudos, a metade do livro posterior, o que nos ajuda a pensar $O$ discurso e a cidade como uma espécie de ampliação de Tese e antítese. Ao falar de Conrad, Candido pretende "mostrar até que ponto ficou normal a visão do homem dividido, e como ela pode dar lugar a técnicas especiais de narração e caracterização literária, de tal forma que o tema e o seu tratamento se condicionam reciprocamente numa unidade expressional indissolúvel". ${ }^{16}$ A observação, como se vê, verdadeira síntese do método crítico de Antonio Candido, vem formulada no livro de 1964 sobre um ensaio cuja primeira versão data de 1957! As datas não mentem: pode ter havido acréscimo de sofisticação nas análises, mas não houve, de modo algum, mudança de postura. Atrás ou à frente, em qualquer fase da obra, palpitarão sempre os conflitos humanos gerados pela vida em sociedade. Outro dado relevante é a epígrafe escolhida para abrir o estudo: "Para a catástrofe, em busca/ Da sobrevivência, nascemos". Os versos, pinçados ao poema "As ruínas de Selinunte", de Murilo Mendes, contêm o título do ensaio. Mais que isto, o belo poema falará do declínio de uma civilização, assunto (como já visto) retomado nas "Quatro esperas" de O discurso e a cidade, o que contribui, ainda mais, para ligar um livro ao outro.

Mas em "Catástrofe e sobrevivência" o ato é um problema decisivo do homem, porque revela sua imperfeição e compromete a virtualidade ideal do ser. ${ }^{17}$ O crítico investiga "os abismos do mundo e do espírito, sondados pelos personagens mais significativos de Conrad como iniciação à humanidade verdadeira". 18 Desconhecidos de nós mesmos, nos surpreendemos em certas situações e frente às reações que temos e aos atos que praticamos. Alguns anos mais tarde, o problema voltaria formulado de outra maneira e em outro contexto. Refiro-me ao estudo sobre Shakespeare, que Antonio Candido publicou com o nome de "A culpa dos reis", na obra coletiva Ética, organizada por Adauto Novaes. ${ }^{19}$ Em Ricardo II, a verdade humana surge do declínio do monarca. O outro, submerso no cargo, "é agora ele próprio", diz o crítico, mas o preço que paga pela recuperação de sua humanidade é a morte. Não estamos distantes do ensaio sobre Conrad, o que dá a medida do esforço permanente de Antonio Candido para explicar a nossa humana condição. E vale a pena mencionar que a análise da peça de Shakespeare foi apresentada originalmente num curso de pós-graduação ministrado por ele em 1968 com o título de "Leitura política de textos literários". ${ }^{20}$ Mais de duas

${ }^{16}$ Tese e antítese, prefácio.

${ }^{17}$ Idem, p. 63.

${ }^{18}$ Idem, p. 78.

${ }^{19}$ Antonio Candido. "A culpa dos reis". In: Adauto Novaes (Org.). Ética, São Paulo, Companhia das Letras/Secretaria Municipal de Cultura, 1992, pp. 87-99.

${ }^{20} \mathrm{Cf}$. Memorial para concurso de professor titular, citado. 
décadas depois, o crítico exporia sua análise para público decerto mais amplo e diversificado, na forma da conferência do curso sobre a Ética, em 1991.

Sem querer cair no excesso, talvez seja pertinente olhar um pouco os contextos da análise (a sala de aula) e da conferência (o ensaio publicado). Em 1968 o poder e o mando vinham sendo sacudidos pelas revoltas sociais que tanto marcaram aquele ano emblemático; em 1991, finalmente redemocratizado, o Brasil havia escolhido um presidente "com aquilo roxo" - autêntica encarnação do mandonismo oligárquico travestido de moderno, encarnação do lado pior, que sempre aflora na vida política brasileira. O estudo sobre Shakespeare fazia-se oportuno, portanto, noutro momento de crise. E chegava a ser premonitório: a queda do rei, analisada na peça, se encontrava, na vida real e contemporânea com a queda do espantalho que governava o país. Em se tratando de Antonio Candido costuma ser assim: trata-se de (aproveitando a feliz expressão de Vinícius Dantas) um "crítico de intervenções". Mais dois exemplos, entre vários outros que poderíamos arrolar aqui: em "A literatura e a formação do homem", conferência de 1972, pronunciada na Sociedade Brasileira para o Progresso da Ciência, então um fórum importante no debate intelectual contra a ditadura, uma das questões centrais é a crítica ao estruturalismo, em moda na época, que desvinculava a análise literária do contexto, num momento em que as Humanidades deviam voltarse para o combate ao obscurantismo da vida brasileira. ${ }^{21}$ Em outra conferência, "O direito à literatura", de 1988, pronunciada na Comissão de Justiça e Paz, órgão da Igreja Católica, e mais um fórum importante na resistência ao arbítrio, o crítico defenderá o acesso à literatura como um direito de todos, comungando, sem cristianismo algum, ideias progressistas de uma igreja voltada para a igualdade entre os homens. ${ }^{22}$

Mas em Tese e antítese, se a síntese não aparece no título é sugerida em "Melodia impura", o derradeiro ensaio do livro, dedicado ao estudo de Stendhal (seus escritos pessoais, críticos e de viagem). Entretanto, trata-se de síntese frágil, ou, para dizer logo o que nos interessa, trata-se de uma síntese discretíssima, delicada, além de dissonante. Para começar, o texto é tratado como "apêndice" e "extraprograma"; além disso, chama a atenção a impureza da melodia no título dado a ele, juntamente com a epígrafe, tirada ao próprio autor: "La beauté est une promesse de bonheur". É que o romancista tratou da busca da felicidade, da possibilidade de plenitude e, logo, da harmonia dos contrários - "desarmonizados" nos ensaios anteriores - de maneira que pudesse revelar a inteireza do ser nos seus personagens. "Todavia", diz Antonio Candido, "sob a força de vontade e firmeza de intuito, surdiam neles minas estranhas, que baralhavam tudo, desviavam a sua virtude da linha reta e o seu ser da inteireza". ${ }^{23}$

${ }^{21}$ Ver Antonio Candido. Textos de intervenção. Seleção, apresentação e notas de Vinicius Dantas. São Paulo, Duas Cidades/Editora 34, 2002, pp. 77-92.

${ }^{22}$ Antonio Candido. Vários escritos. 3a. ed, revista e ampliada. São Paulo, Duas Cidades, 1995. pp. 235-263.

${ }^{23}$ Tese e antítese, prefácio. 
Retomemos então O discurso e a cidade. Diferente de Tese e antítese, onde os ensaios se organizam num só bloco, o livro de 1993, repetindo, se divide em três partes. Se as duas primeiras formarem uma tese e uma antítese, como foi sugerido, é de se esperar que a terceira forme uma síntese, agora um pouco mais evidente que a do livro de 1964. Mas então o que acontece? Depois de tratar de textos do século XX, na segunda parte, Antonio Candido retoma, na terceira, o XIX, desta vez recuando o tempo aos românticos: a "Carta marítima" de Sousa Caldas, vista como um texto modernizante e precursor do Romantismo; a "poesia pantagruélica" dos românticos paulistas; o poema "Pomo do mal" do nosso baudelairiano Fontoura Xavier; e finalmente a poesia itinerante de Mário de Andrade. A razão de o crítico incluir nesta seção de retorno ao passado a análise do poema do poeta modernista revela-se no correr da leitura.

Esta última parte é chamada "Fora do esquadro", porque seus quatro ensaios "falam de obras que remaram contra a maré", ou seja, que navegaram na contracorrente da norma estabelecida. ${ }^{24}$ Os níveis não são iguais, mas são, todas elas, peças de rebeldia. Votando às epígrafes, Calvino e Verdi nos foram apresentados em curiosa inversão: o primeiro, escritor do século XX, para textos do XIX; o segundo, compositor do XIX para textos do século XX. A inversão, outro índice da dissonância do livro, sugere a mistura de procedimentos literários no tempo, que foge à camisa de força da periodização tradicional, uma vez que "os romances naturalistas podem deslizar para as imagens transfiguradoras" (dos romances do século XX), tanto quanto as narrativas mais transfiguradas (do século XX) "penetram bem no real justamente por não terem compromisso documentário". ${ }^{25}$ Quer dizer: realismo e antirrealismo vão entroncar-se nas obras analisadas nas duas primeiras partes do livro (a realidade será sempre o fermento da verossimilhança, e escritores não vivem nas nuvens, nem pairam no céu feito passarinho), tal como o moderno e o tradicional se entroncarão no poema de Mário de Andrade. Será este o sumo da análise feita de "Louvação da tarde", certamente um dos melhores poemas de Mário. ${ }^{26}$

Mas, como não poderia deixar de ser, a epígrafe de "Fora do esquadro" é bastante reveladora. Ela não vem da tradição culta, como as anteriores, e sim do folclore, da canção popular de domínio público: "Por causa do remadô/Madô madô/Que remou contra a maré/Maré maré!". Diferente das outras, agora por outro aspecto, ela não encerra um sentido, não contém uma lição e nada tem de sentenciosa. Limita-se a descrever uma imagem guardada no fundo da memória. Parece um refrão ou recorte de um poema narrativo cujo significado fica no ar: a imagem seria causa ou consequência de um acontecimento que não sabemos qual é? Trata-se, portanto, de um fragmento "desenquadrado", escolhido justa-

${ }^{24} \mathrm{O}$ discurso e a cidade, p. 14.

${ }^{25}$ Idem, ibidem, p. 11.

${ }^{26}$ Possivelmente, o poema começou a ser analisado no curso de Pós-Graduação Análise poética: Mário de Andrade, que Antonio Candido ministrou na USP, em 1963. Ver Memorial para concurso de professor titular, citado. 
mente para anunciar os quatro escritos "fora do esquadro". Como são ensaios sobre obras que remam contra a maré, talvez se explique a combinação de norma e desvio da norma culta nos despretensiosos versinhos. Com efeito, no prefácio ao livro, Candido lembra que os textos fora do esquadro se afastam "em grau maior ou menor das diretrizes predominantes do tempo". ${ }^{27}$ Tais diretrizes são a maré, contra a qual se lança o remador corajoso, no seu canto "inculto", parecido com marchinha de carnaval. ${ }^{28}$ Poderíamos ir mais longe na análise da epígrafe, observando a combinação dos metros populares - redondilha e tetrassílabo - e a sonoridade fechada no canoeiro rebelde, e aberta na maré, símbolo da ordem e plano onde se pronuncia a "desordem". A dissonância, pois, desta parte do livro já começa no dito musical que a introduz.

Voltando então ao que vínhamos dizendo, se as duas primeiras partes puderem funcionar respectivamente como tese e antítese, a terceira poderá funcionar como síntese, embora nada idealista - dissonante, como estamos procurando demonstrar, e mais integrada ao conjunto do livro do que parece à primeira vista. De algum modo a dialética da ordem e da desordem, explicada no estudo de abertura do volume, ${ }^{29}$ reaparece aí, no conjunto dos ensaios finais de $O$ discurso e a cidade, estruturando o livro segundo uma espécie de círculo. A imagem do círculo pode levar à ideia de arredondamento, que não se aplicaria ao livro em questão, pois $O$ discurso e a cidade, como estamos vendo, é obra de exposição de tensões e conflitos, tanto no plano dos temas quanto no das formas que os representam. O leitor encontra, na primeira parte, dois romances brasileiros e dois estrangeiros; na segunda, quatro textos estrangeiros; e na terceira só textos brasileiros. Num presente como o nosso, acometido pela febre de publicações, com livros e mais livros de ensaios, mostrando, em maioria, ajuntamento de escritos, a esmerada organização de $O$ discurso e a cidade chega a surpreender. Trata-se de livro urdido e tramado segundo o senso dos contrários. Nele, o jogo entre simetria e assimetria da forma, ou seja, a escolha do repertório e a disposição dos ensaios espelham a natureza das questões que os mesmos ensaios examinam.

Bem pesados, os textos dessa terceira parte desenham uma pequena história do nosso romantismo "fora da ordem". Pelo menos os três primeiros são amarrados pelo tema da rebeldia. Mas é aí que surge o quarto ensaio, sobre o poema de Mário, provocando dissonância interna no "subconjunto", pois em 1925 o escritor apresentou um poema no qual entronca a estética do seu tempo ao passado romântico. O "fora do esquadro" ganha assim outra configuração: sendo norma modernista "a embriagada aventura do verso livre", ${ }^{30}$ o poeta comparece com uma peça escrita em versos regulares (decassílabos brancos), retomando a

${ }^{27}$ O discurso e a cidade, p. 14.

${ }^{28}$ O leitor poderá cantarolar os versinhos segundo o começo da melodia de "Formosa", de Nássara e J. Rui, antigo sucesso da rádio brasileira.

${ }_{29}$ Obviamente, refiro-me aqui à "Dialética da malandragem", ensaio sobre o romance de Manuel Antonio de Almeida.

${ }^{30} \mathrm{O}$ discurso e a cidade, p. 15. 
tradição - a poesia meditativa estrangeira e brasileira do romantismo, fazendo-se, desta maneira, dissonante. No caso, o convencional da maré de anticonvenção se torna por si mesmo anticonvencional, uma vez crivado de modernidade.

Mário de Andrade é, portanto, o ponto de chegada, como Stendhal havia sido no livro anterior, dessa história de conflitos e dissonâncias: denúncias da vida dura e desorientada dos pobres (primeira parte); fuga da realidade e ameaça de destruição (segunda parte); e rebeldia romântica (terceira). Nessa altura, não seria despropositado dizer que o espírito de Mário talvez seja o elemento ordenador do livro, e de certa maneira de toda a atividade crítica de Antonio Candido. De qualquer modo, foi um homem e um artista dissonante e consoante ao que de melhor podia produzir o seu tempo - pesquisador incansável da cultura brasileira, escritor rebelde e atento aos rumos da arte e do seu país, local e cosmopolita, espécie de "caipira universal", moderno (quando a modernidade não se reduz à moda) e tradicional (quando a tradição se faz contemporânea e enriquece) etc. Quem quiser acompanhar um pouco a conjugação dos dois perfis deve ir ao retrato que Antonio Candido traçou do escritor na época do seu desaparecimento. ${ }^{31}$ Entre outras coisas, o crítico dizia que Mário "tinha o culto da solidariedade humana e [que] só se entenderá sua obra levando isto em conta", que o seu desejo era "o de servir, [de] usar a inteligência, num espírito por assim dizer público"; que Mário abraçava o sentimento "de fraternidade e respeito pelos outros, a que talvez se possa chamar de apreço, no sentido mais lato e forte da palavra". Estou aqui resumindo traços de um retrato bem mais amplo e pungente apenas com o intuito de mostrar que não é difícil perceber, no mesmo retrato, traços do próprio Antonio Candido. Naquele fevereiro de 1946, data do artigo, aos 27 anos, nosso crítico pode ter visto em Mário um modelo a seguir. E o seguiu, como talvez nenhum outro intelectual de sua geração. ${ }^{32}$

De volta aos livros, Tese e antítese e $O$ discurso e a cidade terminam falando da felicidade humana, cuja busca parece ser tarefa inglória, tanto no Romantismo de corte realista de Stendhal quanto no Modernismo de corte romântico de Mário de Andrade. A harmonia do homem, consigo mesmo e com a vida, lembra trabalho de Sísifo e é nessa medida que as "sínteses" dos dois volumes são dissonantes. Nos termos de Antonio Candido, Stendhal criou "uma série de ilusões que lhe

${ }^{31}$ Ver "Lembrança de Mário de Andrade", em Brigada ligeira e outros escritos. São Paulo, Ed. da Unesp, 1992, pp. 209-214

${ }^{32}$ Lembremos o estudante de Direito que, no final dos anos 30, se lança na luta contra a ditadura do Estado Novo; o rapaz que nos anos 40 abraça a causa socialista; o pesquisador e o professor que se debruçam nos estudos do homem e da literatura; o intelectual que combate o arbítrio e o preconceito; o representante da elite ilustrada que se põe ao lado dos desfavorecidos; o militante-fundador de dois partidos políticos que um dia sonharam fazer do Brasil um país mais justo etc. Em todos os recortes de sua trajetória está em causa a luta pela felicidade humana. Ela pode pender para a sociologia e a sociedade, ou para os enigmas da arte e da existência, mas não me lembro de um escrito de Antonio Candido onde não esteja explícita ou latente essa utopia que é dele e deveria ser de todos nós. Sei perfeitamente que a explicação é ampla demais, todavia é preciso considerar que não se vê o problema formulado, com a clareza e insistência com que ele o formulou, em nenhum crítico da sua geração e depois dela. 
permitiram agir e compensar um pesado quinhão de amargura". ${ }^{33}$ Mário, por seu lado, fixou em "Louvação da tarde" um fugaz momento de tranquilidade na vida, através da contemplação momentânea da natureza: "a tarde do nosso poema é o momento do sonho e do devaneio, quando a pessoa concede a si mesma o direito de imaginar qual seria a sua melhor forma, e a imaginação procura afeiçoar o mundo à veleidade. Momento de contemplação serena, pressupondo o esforço de paz interior". ${ }^{34}$

Como se vê, o crítico desindividualiza a situação e o sentimento do poeta: o poema é nosso, o artista é a pessoa, o direito é de todos e a situação é o mundo. A felicidade almejada é fruto do devaneio, não passa de veleidade do indivíduo, mas o indivíduo é o poeta e somos todos nós. Talvez a busca seja um gasto inútil de energia e, no entanto, dos mais humanos e legítimos.

O poeta vai transitando num automóvel, entre cafezais, rumo à sede de uma fazenda, com plena consciência de estar vivendo um bom momento, embora este seja passageiro, como a tarde. Por este motivo aceita, e aproveita, o instante em que, suspenso do "tumulto da vida", ${ }^{35}$ sente-se "forte, saudável, bonito, chegando a superar as frustrações amorosas". ${ }^{36}$ Trata-se de "fuga provisória do real", 37 mas de um provisório construtivo, porque gera o poema, que por sua vez é trabalho e, como tal, atividade do dia: "De dia eu faço, mas de tarde eu sonho". A questão, portanto, é sonhar para poder fazer. Melhor ainda: o sonho não descarta a vigilância, a consciência de estar sonhando e criando a um só tempo. ${ }^{38}$ No fundo, Mário descreve uma cena de entrega, sem entregar-se totalmente, o que pode dar a medida da sua modernidade. Por este prisma, ele atualiza a amargura de Stendhal, encarando com serenidade, embora alerta, a fugacidade do momento quase pleno. De certo modo o poeta moderno anestesia a antiga dor, que sabe não ter cura. E pelo mesmo prisma, juntamos as figuras dos dois artistas rebeldes e os finais dos dois livros, duas obras-primas de um crítico igualmente rebelde, moderno e dissonante. Como acabamos de ver, $O$ discurso e a cidade termina num momento de paz, ou melhor, de trégua fugidia, como a tarde mostrada no poema de Mário de Andrade.

${ }^{33}$ Tese e antítese, prefácio.

${ }^{34} \mathrm{O}$ discurso e a cidade, p. 268.

${ }^{35}$ Idem, ibidem, p. 270.

${ }^{36}$ Idem, ibidem, p. 271.

${ }^{37}$ Idem, ibidem, p. 277.

${ }^{38}$ Noutro texto, Antonio Candido dirá: "a literatura é o sonho acordado das civilizações". Ver "O direito à literatura", citado, pp. 242-243. 